the git. Of course, it was the duty of the engineer to stop the cngine as soon as he had arrived at the upper regions, the connes, but the duty was neglected. In consegrence of which negligence, the man was carried up and forced between the roller, round which the rope was being wound, and the beam above. The back part of his head wme into contact with the beam, and the head was forced down upon the chest. In that position his body was drawn through so narrow a space, that I should be afraid to say hom narror, lest I should seem to state an impossibility, but certainly it was not greater than ten or eleven inches.

When I first saw him, two or three hours after the accidont, he was perfectly sensible, but complained of great pain in the neck. He had but little power of motion in the left arm, none in the right, or in either of the legs, but sensibility to touch remained in all. His respiration was quite natural, and excepting the pain in the neck and the paralytic condition of the extremities, he did not appear to be much injured. On the day following, I found him in much the same state, and it was necessary to introduce the catheter. From that time he gradually improved, and reguired little assistance of any kind. In about a fortnight he was so far recovered as to be able to walk about-weak, certainly, in his legs, but able to walk without assistance.

In this case, the cerebral vertebre by being bent and doubled upon the chest, caused the spinal cord to be so much stretched and strained as to induce temporary paralysis; but the injury fortunately was not so great as to be irreparable by the vis medicatrix naturce.

These few cases have been selected from many, not becase there was anything peculiar either in their nature, their treatment, or that they were likely to prove practically useful and instructive, but because they appear to support the opinions, that miners endure severe injuries with less outward exhibition of suffering than others, and also recover from accidents of so much severity that they would in all probability have been fatal if they had occurred to individuals whose physical frames had been less hardily educated, and whose intellects more highly developed. I have therefore not thought it necessary to enter into minute details with regard to the treatment, or to give more than a slight sketch of the prominent features of each case.

When we consider the mode in which hour after hour of the miner's gloomy and monotonous existence is spent, in darkness, or with light serving but to render "darkness visible", picking out masses of coal from the gloomy stratifications spread around and above them, frequently pursuing their work in silence and solitude, and sometimes in mines so shallow as to compel them to work either sitting on their heels or almost prostrate, according to the height of the roof or thickness of the bed of coal.* A life so spent must exhibit few opportunities of calling out and cultivating the sensibilities of the nerrous system; on the contrary, the tendency must be to depress its natural activity, and to render it less sensitive, in short, apathetic. They are indifferent to danger; they face their last enemy, death, and shrink not. Whether it be, because life is indifferent to them, having so few moments of enjoyment; or whether it arise from that apathetic state, before mentioned, I know not; but certain I am, it exists in a greater degree than $I$ find it in those of higher rank and more cultivated intellect. The North American Indian is said to face death in its most terrible shape with calmness, and to endure torments the most horrible with the greatest sang froid. I do not consider these powers of endurance in the miner or the Red Indian to be the result of heroic fortitude, or a higher cast of mind, but their nervous systems being less developed, there is, consequently, less pain to bear from the same amount of violence and injury than there would be if inflicted upon others, whose nervous systems have been differently educated. It may be good poetry to exclaim, that the "beetle suffers a pang as great

- Many of the mines worked ars not more than twenty inches in thickness. as when a giant dies", but I feel atisfied that it is not good physiology.

I attribute also the frequent recoveries of miners from injuries, that would probably have been fatal to others, to their comparative insensibility to pain. They foel loes; therefore the organic functions go on with less irregularity and disturbance than they would do, were their minds harrassed and disturbed with apprehension, and their bodies racked with pain. In the evening, when the day's toil is over, this class of workmen do not appear to exhibit much vivacity and energy. They are frequently seen sitting upon their heels, in the position in which many of them are constrained to work, smoking their pipes or quietly inhaling the summer evening's breeze.

In the above remarks, I do not wish to be understood as intending to assert that all colliers or miners exist in such an unintellectual and apathetic state; there are no doubt many exceptions; but I feel satisfied that the majority are very low in the scale of intellectual culture, and that the nature of their occupation is such that we might almost have predicted that such a mental condition must ineritably be the result of such an occupation.

Bolton-le-Moors, September 20th, 1855.<smiles>CC</smiles>

\section{ON EMBRYOTOMY IN PRESENTATIONS OF THE SUPERIOR EXTREMITIES.}

By J. G. SWAYNF, M.D., Physician Accoucheur to the Bristol General Hospital; and Lecturer on Midwifery, etc., at the Bristol Medical School.

[Read at the Quarterly Meeting of the Bath and Bristol Branch, September 1855.]

Ir arm-presentations, when turning is impracticable, as in head-presentations which do not yield to the forceps, the last resource of the accoucheur is embryotomy. In either case, the operation consists of two distinct processes, viz., evisceration and extraction; performed somewhat differently, however, in the one case, as compared to the other.

The remarks I am about to offer will refer solely to embryotomy in arm-presentations; and it will be my object to show that the extractive part of this operation ought to be conducted upon precisely the same mechanical principles as those which nature adopts in what is termed "spontaneous evolution" of the foetus. The three following cases will serve as illustrations; the first is one of spontaneous evolution, and occurred to one of my pupils (Mr. Dymoke) upon whose accuracy of observation I can place implicit reliance. I therefore relate it in his owu words.

CASE I. "I was called to see Emma A., about. 5 A.X., August 10th, 1852, when I found her in active labour. Upon examination, I discovered that the membranes were ruptured, and the right shoulder presenting, I directly set about attempting to turn the presentation; but, owing to the pains being very strong and continuous, I could not succeed in bringing down the feet, or in altering the position of the child. The labour advanced quickly and easily into the second stage, and the shoulder protruded from the vagina. Shortly afterwards the arm prolapsed. The child remained some time in this position; and, the pain being very strong, the body of the child was forced down lower and lower in the pelvis, until it protruded, the right side being the prominent part, and the arm and shoulder remaining all the time, as at first, outside the vagina. The child remained in this position for some time, gradually descending, and becoming doubled completely backwards. I then assisted as well as I could in furthering the descent of the hips, and by supporting the perinæum; and the child was born about 8 A.M., the hips and knees bent up coming first, and then the feet, without any alteration in the position of the presenting arm and shoulder. The child was dead, the circulation in the cord having been stopped by pressure (it grasped my finger with its hand when that part first appeared). It was a male child, and a fine one. There was no laceration of the coft parts of the mother; no 
hrimorrhege; placenta came sway easily. The mother did exceedingly well after delivery."

In the two next cases, the arm also presented; but evisceration was had recourse to because it was found impossible to turn.

Casn Ir. Mrs. A., George Street, a patient of the Bristol Iying-in Institution. Labour pains first commenced on Friday morning, December $9 \mathrm{th}, 1853$; they continued at intervals during that day and night. On Saturday morning she sent for the midwife, who arrived about 11 A.M. The membranes ruptured at 1 P.M.; and the pains continued at intervals, but were rather feeble. The midwife discorered what she thought was a knee presenting, but which was in reality an elbow. She did not find out her mistake until 11 P.x., when the right arm prolapsed externally; she therefore sent off for Mr. Challacombe, who arrived about 12 that night. He immediately attempted to turn, but without success; and he therefore called in Mr. Hawkins, who also made several attempts to turn, but failed. They sent up for me about $10 \frac{1}{2}$ A.M. December 11 th. When I arrived, I found the right arm prolapsing, and very much arrived, back of the child was situated posteriorly, the head being over the right pubic eminence, and the feet towards the left iliac fossa. I introduced my left hand with the greatest difficulty, notwithstanding that the womau was put under the influence of chloroform. The contraction of the uterus was so great, that by the time I could reach the left ilium of the child, my hand was so benumbed by the pressure as to be rendered completely useless. I therefore withdrew it. Upon consultation, we determined to open the thorax and eviscerate. Accordingly, I punctured the right axilla with Smellie's scissors, and divided one or two of the ribs. I then, with the help of the crochet, extracted some of the contents of the thorax and abdomen. I fixed the hook round the vertebral column in the dorsal region, but could not extract the trunk until I had divided the spine hy means of a pair of bone nippers. I then fixed the hook in the lower portion of the vertebral column, and drew it down behind the other portion; and in this way was able to extract the inferior part of the child by the side of the arm, which still remained in the vagina. The remainder of the child was then extracted (l P.M.). It was a female, apparently two or three weeks before the full time. The placenta came away without any difficulty. We then gave the patient an opiate with some brandy. With the exception of some abdominal pain on the next day, which was reliered by an opiate, she recovered without an unfavourable synptom.

Case III. On Thursday, February 1st, 185j, Mr. Lancaster called me in to a patient (Mary B.), who in the first instance had been attended by a midwife. She was not married, and had concealed her pregnancy from those in the house where she was at service. The inembranes ruptured on the Saturday preceding, and the labour proceeded very slowly from that time until the Thursday, when the nture of the case becoming evident, a midwife was sent for, who, finding the arm presenting, sent for Mr. Lancaster. As the arm had for a long time protruded, Mr. L. could not succeed in turning; and, thinking it a case for evisceration, requested my attendance. When I arrived, I found the left arm presenting, the palm of the hand looking backwards; the arm was protruded even beyond the shoulder. The right clavicle pressed against the ramus of the right pubes, and the head was towards the left ilium. The body was so closely jammed into the pelvis, and the waters had been so long evacuated, that I found it impossible to turn with either hand. The patient was now very restless and excited; the pulse 140 ; tongue dry, and covered with a brown fur; with considerable codema of the eyelids, and some heat and tenderness of the soft parts. We therefore deemed it inexpedient to wait any longer, and decided upon evisceration. Accordingly, I opened the chest of the child with Smellie's scissors in the left axilla; and then, passing a strong pair of ordinary scissors through the opening, I divided the spine and sereral of the ribs, and drew out with my finger and with the crochet the thoracic and a considerable portion of the abdominal viscera. Nevertheleas,
I could not succeed in bringing away the child until I had cut through the sternum also. I was thus enabled to double the hody completely, and then to bring down the inferior portion with the crochet behind the other. The rest of the labour was soon completed. The patient recovered slowly; some sloughing of the upper wall of the ragins ensued, which produced a small fistulous communication with the bladder, which remained pervious for some weeks. She also complained of numbness and loss of power in the right leg.

The first case shows well the correctness of Dr. Douglas' explanation of what Denman termed "spontaneous evolution". In 1811, Dr. Douglas pointed out that the fotus in these cases does not undergo a natural process of turning, as Denman supposed; and therefore, that the term spontaneous expulsion is preferable to that of spontaneous evolution. He showed that the presenting arm, instead of being retracted, is protruded more and more, until the shoulder and clavicle become fixed beneath the arch of the pubes, and form an axis around which the fotal body revolves, and glides along the carity of the sacrum, as the trunk is pressed more and more into the pelvis with the pains. In this way the side of the thorax, the back, the breech, and the inferior extremities, successively appear, and are expelled behind the presenting arm; the other arm and the head, which until now had remained fixed behind the pubes, being expelled last. It must be plain, from the very nature of its mechanism, that spontaneous expulsion can be but a very rare and exceptional termination of transverse presentations which are left to nature. If the mother's pelvis and the child are of usual size, it can only take place by an extreme flexion of the child's body, such as an ordinary vertebral column will scarcely admit of, especially in a lateral direction, and such as would almost infallibly destroy the life of the child. When it does take place, the mother's pelvis is generally larger than usual, or the child smaller, and very probably dead, and on that account more flexible. There is little doubt that, if these presentations were abandoned to nature, in nine cases out of ten delivery would not take place, and both mother and child would be sacrificed.

The obvious duty of the accoucheur is to turn; and, if he cannot do that, to eviscerate. To perform the latter operation properly, he must imitate as closely as possible the mechanism of spontaneous expulsion. To understand this, we must consider what are the mechanical obstacles which, in nine cases out of ten, would prevent a transverse presentation from being expelled by the powers of nature. I believe that the principal obstacle will almost invariably be found, not so much in the bulk of the child's body, as in its inflexibility. From the way in which the child's body presents, the spine is placed right across the brim of the pelvis, in the most unfavourable position that is possible; so much so, that it will scarcely ever bend upon itself sufficiently to allow of that doubling of the body which is necessary for spontaneous expulsion. The obvious indications, therefore, in operating, are, first, to diminish the bulk of the child by evisceration; and secondly, which is of far more importance, to increase its tlexibility by division of the spine. If the accoucheur is content with simply opening the thorax and removing some of the viscera, he will almost certainly be foiled in his attempts to effect delivery. This conviction has been strongly impressed upon my own mind by the circumstances of a trial at Wells, in 1852 , at which I was present. With respect to the causes of the trial, I need not now say more than that it arose out of a fatal case of midwifery, in which the conduct of the medical man who attended had been called in question. The case was one of arm-presentation; the medical man in attendance attempted to turn, and failed; he then opened the chest and eviscerated, but did not divide the spine, and consequently failed iu accomplishing delivery. Another medical man was called in; and, after dividing the spine, succeeded in delivering the woman. In my own two cases, related above, it was impossible to extract the body without dividing the spine;

ชิ 
and in the third ance, the starnum aloo. I hare ley great then upon the necessity of dividing the spine, becsuse in al the Inglich books on midwifery which are in common une this part of the operation is altogether omitted.

Zfter evisceration and division of the spine, the extraction of the child's body is also to be made in imitation of the mechanism of spontaneous expulsion. The hook is to be fixed into the lower part of the spine, and the lower part of the body to be drawn down into the hollow of the sacrum and through the os externum, behind the upper part of the thorax and the presenting arm. This part of the operation does not usually present much difficulty.

Although embryotony in transverse presentations is a proceeding which must be very repugnant to the feelings of the accoucheur, and one which he ought not to undertake without a consultation, $y$ et it does not involve the same amount of responsibility as craniotomy. In arm presentations, when the waters have long escaped, and the uterus has contracted very closely around the child, the great pressure upon the cord will nearly always destroy the life of the child. In all such cases of unusual difficilty which have occurred to myself, and in which I hare managed to turn, the child has been still-born; and, I have no doubt, from this cause. So that if the accoucheur can succeed in turning, he will rarely be able to save the life of the child. Still, however, if he can turn without violence, and without unduly risking the safety of the mother, it is far better to do so than to perform embryotomy. But, if he cannot do so without great force, it is far preferable at once to perform embryotomy, which is a tolerably safe operation for the mother, than to push the hand into the uterus, in order to turn at all hazards, with a certainty of bringing into the world a dead child, and a great probability of causing the death of the mother.

Bristol, Octuber 1855.

\section{ON A NEW FORM OF ARTIFICIAL MEMBRANA TYMPANI.}

By THOMAS WESTROPP, Esq.

Arr artificial contrivance that promises to supply the loss of any particular part of the human body demands attention, and its merits should be fairly tested; but though it should not fulfil all the functions of the original organisation, which it could hardly be expected to do, or though it should not come up to the praises of its too confident inventor, or the expectations of those requiring its aid, still, if it confer a considerable amount of benefit, without any great discomfort in its application, we may fairly say that science has advanced a step in lending her aid to alleviate the ills to which flesh is heir.

I desire to call the attention of the profession, and those engaged in the aural department in particular, to a mechanical invention which has occupied my mind for some years, and has been tested in practice of late, though not by any means as extensively as I should wish. I would premise that two varieties of artificial tympana are used by aurists the medical profession in general, unfortunately, do not strive to advance our limited acquaintance of ear disease; or, still more unfortunately, do not endeavour to carry out the treatment as at present recommended by the best authorities; the consequence is, that aural surgery is rather in the background, and the sufferers fall daily into the hands of rapacious and lying quacks.

The first contrivance we know of is the moist cotton plan. Mr. Yearsley, of London, has the credit of being the first to publish it, though I have reason to believe it was known previous to his account; however, I do not want to detract in any degree from his merit. This plan consists in placing a very small bit of fine cotton wool moistened with some unctuous fluid in the position of the lost membrane, or where a perforation only exists, on it. It would take too long were I now to enter into all the particulars of the diseases causing this accident; it is described in various treatises on acoustic medicine. In certain cases of partial deafness, a great increase of hearing is the result ; in others, even when we do not accortain any epecial cause why it should not succeed, no benefit is derived; of course, a grent deal has been said on this subject, but I would merely romark that we are most likely to be successful where the perforation in the membrane is small, and where chronic disease has not disorganised the other complicated structures of the ear or its appendages; still, in very apparently hopeless cases of lost membrane, the moistened cotton, if properly placed in the site of the original, produces results more or less satisfactory. One of the adventages of this mode of treatment is, that the appliance is easily made by an intelligent patient, who may become more dexterous in hitting off the exact distance within the meatus than his adviser; but it requires to be frequently renewed, as the cotton becomes displaced and soiled, so as to render necessary a constant supply of cotton-wool and oil, or glycerine. It is also a question whether a plug of cotton filling up a large space in the meatus, and resembling more a wet sponge than a vibrating thin membrane, though it improves the hearing of a very deaf person, and is, therefore, of some use, and better than nothing, still causes the sounds conreyed to the ear to be heard indistinctly, and with a muffled accompaniment, which may be dispensed with by using a more perfect apparatus in connexion with the organ of hearing, and which I am now about to describe.

Several years since, during my pupilage with a distinguished oculist and aurist, it struck me that some more permanent structure, and one more resembling the real membrana tympani might be got up and placed in situ, instead of cotton. I was inclined to think that some matorial having the property of vibrating, and one resembling in its structure, thickness, and appearance, nature's contrivance, should, on principle, be best adapted for the purpose. Never having, till of late years, an opportunity of testing these tympana, the idea remained dormant in $\mathrm{mJ}$ mind for a long time; in the interim, Mr. Toynbee published his ideas, and an account of the peculiar contrivance he had invented. That the same investigation, leading to similar results, may be the work of two or more individuals, unknown to each other, is a well known fact. Some wonderful discoveries in the astronomical world have been brought to light by professors of different countries nearly at the sume time, without either being aware of the other's labours.

My first idea was to cut out a circular flat piece of some material, India rubler, gutta percha, or such like, and press it down to the site of the lost membrana tympani. In order to make it as like as possible to the real one, I coated its edges repeatedly with gutta percha dissolved in chloroform, so as to form a ring very analogous to the fibrous ring met with in the dissection of meatus and membrana tympani; now though this looks very well on paper, and was a close imitation of uature, I must confess, after patient and careful manipulation of it in the ears of patients, it did not equal my expectations at all. This was owing to two causes; first, if we recollect the anatomy of the meatus, we must remember that it is narrower in the centre than within, where the nembrana tympani is inserted, or without where it is of cousiderably greater diameter. Besides this impediment, there is another, specially intended by nature to impede the entrance of foreign bodies, namely, the curvature, which is thus described by a late author: "The meatus is ovoid in calibre externally, but becoming circular towards its distal end, and leading from the concha externally, at first a little forward and upwards, then backwards and inwards, and again turning downwards, forwards, and inwards to the membrana tympani, which separates it from the middle ear." Were it not for the narrowing at the centre, the curve could be easily overcome; but as it is, they assist each other in rendering the proper insertion of any flat artificial membranes almost impossible. I always found flat bits of any material, whether cut circular or oval, double up, extremely difficult to place at the natural angle, and at the proper site; in addition, the hearing was not satisfactorily improved; this I accounted for by the fact, that the intended septum between the meatus and 